\title{
Before Finding the Support Groups... I was in the Worst Year of almost 40 Years of CCH (Chronic Cluster Headaches)
}

\section{Conceptual Paper}

Enduring these incredibly violent and brutal attacks every time I hit REM sleep and several more daily and nightly averaging a dozen a day and most all were over an 8 for a solid year. These were not the same 10's I had for 38 years, These were something else and so much more powerful than I was used to throughout that year. My CCH (chronic cluster headaches) started in 1973 at age 14, I'm 56 now.

I was completely and utterly terrified to lay down and was actually passing out from some incredibly brutal attacks waking

up on my kitchen floor. On one of those I woke up and blood everywhere as I guess I hit my head on the edge of the counter while blacking out getting a huge gash on my head. It was just something I knew I wasn't able to keep doing and was like nothing I ever felt in all those years of thousands of attacks. It was beyond brutal and had me so scared and in total awe of the power.

To try to lay down and sleep, $95 \%$ of the time when hitting REM sleep it would wake me in screaming, crying excruciating agony within 10 to 15 minutes of falling asleep almost every single time for a year. So much fear of getting another of these insane attacks that I didn't even attempt to sleep or even lay down for 6 weeks ending up in the hospital for a week from severe sleep deprivation and fluid gain. I had fluid around my heart sack and in my lungs and you could push my skin down anywhere and it would leave an inch deep finger print that would stay for several minutes. I put on around 30 to $40 \mathrm{lbs}$ in that 6 weeks (mostly fluid).

My son gave me his laptop to look for help. I was not up until then a computer guy and had rarely ever used one. I had no idea CH support groups existed and when I learned how to use it, I would sit at the computer day and night, passing out from exhaustion and even sitting in my chair and passing out the beast would wake me with another 10 . I tried everything to sleep. In my lazy boy, tons of pillows so I could sleep sitting up and on and on.

I was absolutely, completely and ultimately done. I knew I couldn't keep it up any longer it was plain and simple it was too much for me to handle and complete loss of any quality of life and the pain had me screaming day and night. Also going through this after 17 major operations and having another form/s of severe chronic pain from nerve damage that had me at a constant 7-8 on its own $24 / 7365$. If I had to choose between going through those 17 major operations again or that year of those incredible attacks. It is easy, I would do the operations and these were brutal operations opening my abdomen.

Conceptual Paper
Special Issue - 2016
John Fletcher*
President/Founder, Cluster Headache Foundation Inc., USA
*Corresponding author: John Fletcher, President/
Founder Cluster Headache Foundation Inc., USA, Email:
clusterheadaches@yahoo.com
Received: December 18, 2015 | Published: April 06, 2016

Some may think this is an exaggeration, but actually just the opposite... I am having difficulty expressing just how messed up this whole situation was. I wanted to die, I couldn't take it anymore and I know I'm not alone having this horrible scenario of the worst pain known getting even worse because of medications. I wrote this just as a caution to anyone out there dealing with this same or similar situation.

Some may be wondering how it got so bad and I'm certain it was $400 \mathrm{mg}$ of Topamax and $1200 \mathrm{mg}$ of Depakote that turned my $\mathrm{CCH}$ into something completely different and I was still in that ignorant mode of listening and doing what I was told and really didn't even realize it could have been these meds doing this to me. It's the only thing that could have possibly caused these mega hits I was having and it all started like this shortly after starting the Topamax. After about 6 months of getting worse, my doctor added $1200 \mathrm{mg}$ of Depakote and that put my CCH into a place I hope I never see again.

I know some of you can relate to this, but until you have realized like I did that as bad as $\mathrm{CH}$ can seem to get and how powerful attacks can seem to be. It can get worse and some medicines or combinations of medicines prescribed to "Help" can cause this to happen. I'm certain it was these medications that made things so much worse, so just beware that it can happen and can really take you by surprise, I didn't have a clue at the time, just thought my CCH changed and this was going to be my life. When I realized that and I was trying to figure out how I was going to "check out" and after my son had given me his laptop and learning how to use it for a while then finally finding $\mathrm{CH}$ dot com. I went there for the first time and saw this treatment called the "Vitamin D3 Anti-Inflammatory Regimen" and contacted Pete Batch... He saved my life.

The regimen saved my life as I went totally $\mathrm{CCH}$ free in 3 days and stayed that way for a year and a half. It was the biggest turning point I ever had in my life by far. I literally had three things I put 
in front of myself that would have done the job and I still have those 3 things in my drawer to remind me of just how bad things can really get. I'm sorry if this scares anyone but the facts are we have treatments that work. I also realize we are all different and I know some CHers that absolutely nothing works and I fear for those fellow sufferers.

Even after years and years of searching for the medicine that will bring relief without luck, never give up! Seriously, it took me $38+$ years to finally find a medicine that helped me and didn't make things worse. I had given up so many times to the other monster "Depression". When you do find the treatment that brings relief or remission, it can be such an incredibly profound thing after searching in desperation for so many years for nothing, then finding it will bring tears of pure joy to your eyes to finally feel that incredibly precious, precious, PRECIOUS relief...

I think that if I was to make a point of all this it would be...
Beware of medications that make your $\mathrm{CH}$ worse... Also we have treatment options with incredible success rates. Don't give up! EDUCATION. Finding a support group and meeting the "Family" for the first time is life changing. Just the fact of not being alone anymore can change everything and hope is a very, very powerful thing and not a fleeting glimpse of it either, grab it, hold on to it and do not let go... Being in a support group has incredible power to help yourself and others completely turn their lives around and I see it every day.

For those new to $\mathrm{CH}$, you will find hope and just being in a group will cut years of unnecessary suffering and you will have found what it took a lifetime for many. For you old timers beware that even though you think you have seen it all and everything the beast can do...You probably haven't and that with no disrespect at all, just a caution. 